\title{
BMJ Global Health Conflicts of interest are harming maternal and child health: time for scientific journals to end relationships with manufacturers of breast- milk substitutes
}

\author{
Catherine Pereira-Kotze (D) , ${ }^{1}$ Bill Jeffery (D) ${ }^{2}$ Jane Badham, ${ }^{3}$ \\ Elizabeth C Swart (D) , ${ }^{4}$ Lisanne du Plessis (D) , ${ }^{5}$ Ameena Goga (D) ,,7 \\ Lori Lake (D) , ${ }^{8}$ Max Kroon, ${ }^{9}$ Haroon Saloojee (i) , ${ }^{10}$ Christiaan Scott (D) , ${ }^{11,12}$ \\ Raul Mercer (D) , ${ }^{13}$ Tony Waterston (D) , Jeffrey Goldhagen (D) , ${ }^{15,16}$ David Clark, ${ }^{17}$ \\ Phillip Baker (1) , ${ }^{18}$ Tanya Doherty (D) ${ }^{1,19}$
}

To cite: Pereira-Kotze C, Jeffery B, Badham J, et al. Conflicts of interest are harming maternal and child health: time for scientific journals to end relationships with manufacturers of breast-milk substitutes. BMJ Global Health 2022;7:e008002. doi:10.1136/ bmjgh-2021-008002

Handling editor Seye Abimbola

Received 15 November 2021 Accepted 24 November 2021

\section{Check for updates}

(c) Author(s) (or their employer(s)) 2022. Re-use permitted under CC BY-NC. No commercial re-use. See rights and permissions. Published by BMJ.

For numbered affiliations see end of article.

\section{Correspondence to} Ms Catherine Pereira-Kotze; catherinejanepereira@gmail. com
The promotion and support of breastfeeding globally is thwarted by the USD $\$ 57$ billion (and growing) formula industry that engages in overt and covert advertising and promotion as well as extensive political activity to foster policy environments conducive to market growth. ${ }^{1}$ This includes health professional financing and engagement through courses, e-learning platforms, sponsorship of conferences and health professional associations ${ }^{2}$ and advertising in medical/health journals. These contribute to the overuse of specialised formulas ${ }^{3}$ and inappropriate dissemination of health and nutrition claims. ${ }^{4}$ Such 'medical marketing' reduces breastfeeding initiation, exclusivity, and duration, irrespective of country context. ${ }^{5}$ It also creates a subtle, unconscious bias and conflict of interest, whereby journal publishers may consciously, or unconsciously, favour corporations in ways that undermine scientific integrity and editorial independence-even perceived conflicts of interest may tarnish the reputation of scientists, organisations or corporations. Such conflicts have plagued infant and young child nutrition science for decades. ${ }^{6}$ Consequently, the World Health Organization (WHO) and United Nations Office of the High Commissioner for Human Rights recommend measures to avoid conflict of interest in nutrition policy development and service delivery as well as professional education and research. ${ }^{78}$ While perceived conflict of interest generally does not involve financial payment, the WHO defined actual conflict of interest as arising "when a vested interest has

\section{Summary box}

Forty years after the World Health Assembly adopted the International Code of Marketing of Breast-milk Substitutes, inappropriate marketing of breast-milk substitutes persists and puts infants and young children at risk of malnutrition, illness and death.

- The formula industry is large and powerful and has used various 'medical marketing' strategies to influence scientists and health professionals as to the purported benefit of breast-milk substitutes.

- The examples provided in this commentary show how a manufacturer is using a leading scientific journal to market breast-milk substitutes through paid advertisements and advertisement features.

- By receiving funding from breast-milk substitute manufacturers, journals create a conflict of interest, whereby the publisher and readers of the journal may favour corporations consciously or unconsciously in ways that undermine scientific integrity, editorial independence and clinical judgement.

- Conflicts of interest have previously been identified in infant and young child nutrition science and in journal advertising policies and have been criticised by public health experts, yet the practice continues.

- All scientific journals and publishers should stop accepting funding from manufacturers and distributors of breast-milk substitutes, in accordance with global public health guidance. Public health must come before profit.

the potential to unduly influence official or agency judgement/action through the monetary or material benefits it confers on the official or agency." 9

The public health importance of breastfeeding is undisputed. Creating an 


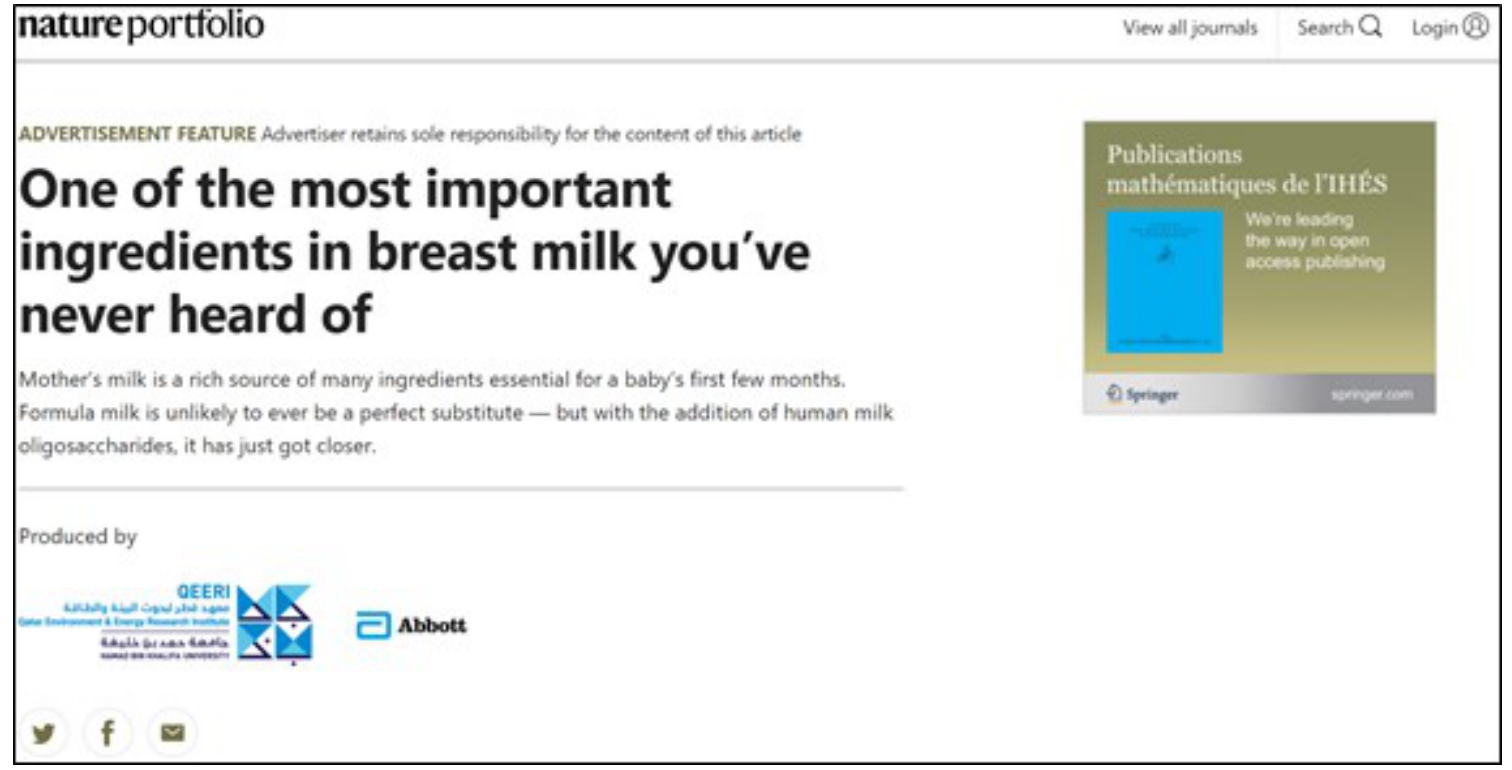

Figure 1 An open-access advertisement published on the Nature website. https://www.nature.com/articles/d42473-01800007-1

environment that supports and protects breastfeeding is essential to ensuring every child's right to the highest attainable standard of health. Companies that advertise amd promote their breast-milk substitutes in ways that contravene the International Code of Marketing of Breastmilk Substitutes (the Code) ${ }^{10}$ violate the rights of children to be fed in the best possible way, and of mothers to make informed decisions about infant feeding. ${ }^{7}$ There is something amiss with global health when academic journals advertise and have sponsorship policies that directly conflict with public health guidance. We are aware of one study on infant formula advertising in medical journals and although it reported that breast-milk substitute advertising in journals was uncommon, adverts identified were poorly compliant with the Code. ${ }^{11}{ }^{12}$ We use two examples to illustrate journal adverts that violate the Code: in May 2018, Nature, a high-impact factor and widely read publisher with numerous subspecialty journals, published an open-access advertisement about formula milk, with the subtitle 'Mother's milk is a rich source of many ingredients...Formula milk is unlikely to ever be a perfect substitute - but with the addition of human milk oligosaccharides, it has just got closer'. (figure 1). Implying that formula is close to mother's milk could influence health professionals' perceptions and infant feeding counselling. Furthermore, because these sugars are sythesised in the laboratory, the claim that these are 'human milk oligosaccharides' is itself misleading and possibly contrary to consumer protection and food laws in many countries where misleading or deceptive claims are prohibited. Such advertising is contrary to provisions of the Code, national laws in at least 89 countries and arguably European Union law (where Nature is published). ${ }^{13} 14$ For instance, Article 7.2 of the Code states that "Information provided by manufacturers and distributors to health professionals regarding products within the scope of this Code should be restricted to scientific and factual matters, and such information should not imply or create a belief that bottle-feeding is equivalent or superior to breastfeeding." Article 10 of the EU Regulation 609 of 2013 also states that " 1 . The labelling, presentation and advertising of infant formula and follow-on formula shall be designed so as not to discourage breastfeeding. 2. The labelling, presentation and advertising of infant formula, and the labelling of follow-on formula shall not include pictures of infants, or other pictures or text which may idealise the use of such formulae." ${ }^{15}$ Likewise, subsection 21(3) of The Infant Formula and Follow-on Formula (England) Regulations 2007 states if advertised in a scientific publication, "Information in advertisements for infant formula shall not imply or create a belief that bottle-feeding is equivalent or superior to breastfeeding." 16 The use of the terms "it has just got closer" in the advert clearly implies equivalency between breastfeeding and formula milk or, at best, meaningful proximity to infant formula and, as such, are contrary to the Code, and binding EU and UK law. Furthermore, the advertisement does not contain any of the information required by Article 4.2 of the Code, including, for example, the health hazards of unnecessary or improper use of infant formula and other breast-milk substitutes.

The second example of BMS advertising in a scientific journal that we highlight is the recent public and sponsored Nature Research Custom Media Facebook post, which referred to an advertisementfeature (figure 2) titled 'Examining breastmilk for clues in the fight against food allergies' with the subtitle 'Research examining the roles of human milk oligosaccharides in infant immunity suggests that these breastmilk components may help suppress allergic responses and boost gut health' (figure 2). The title of the advert is misleading as it suggests that the article is about breastmilk yet the focus is on synthetic oligosaccharides. The 


\section{Examining breastmilk for clues in the fight against food allergies}

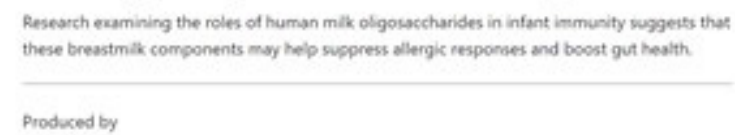

nature research custom media

Abbott

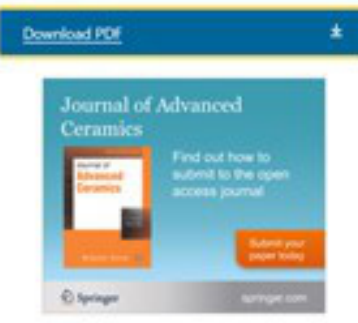

\& $a$

Figure 2 An advertisement feature published on the Nature website produced by Nature Research Custom Media. https:// www.nature.com/articles/d42473-020-00362-y

advert implies that a commercial preparation can mimic and substitute the proven, complex, and dynamic natural food matrix that is human breastmilk which is conjecture that is not supported by the best available evidence. ${ }^{17}$ Furthermore, the information provided in the advert is also an illegal claim in many of the jurisdictions where Nature is read. Both advertorials depicted here include photographs of young children, a clear violation of EU law and the Code.

These 'advertisement features' combine editorial style presentation with advertising content and serve to normalise formula milk for health professionals who are opinion leaders in communities and health systems. Fine-print stating that the advertiser is responsible for the content is obscured by large print headlines, sentimental pictures and imperious proclamations about scientific findings. Scientific journals carry authority and credibility among health professionals because they are presumed to report carefully considered, rigorous, peerreviewed independent scientific analyses. The use of the term 'article' in the URLs for both advertisements and the inclusion of numerous formal scientific citations in a peer-reviewed journal also bolster the appearance that these advertisements won publication in a prestigious journal through scientific rigour, not the payment of a large fee. The examples cited risk jeopardising both infant health and the integrity of the scientific publishers. The Facebook post further promotes the 'Abbott Nutrition Health Institute' website enticing readers to use this source to obtain additional information that is solely commercial in nature.

Risks of promoting breast-milk substitutes are especially consequential in low-and middle-income countries where access to healthcare is poor, and malnutrition in all forms is prevalent. Feeding with breast-milk substitues is not affordable nor sustainable for most low-and middle-income countries' populations and results in increased infant morbidity and mortality. Given these vulnerabilities, scientific journals have a professional and ethical responsibility to put additional protections in place to ensure that their brands are not associated with misleading advertising claims and to warn readers of the high risks associated with suboptimal breastfeeding. ${ }^{18}$

An initial email submitted to Nature raising our concern received a reply that this would be considered by the editorial team; however, after numerous exchanges and nearly a year later, the advertisements remain on the site. These advertisements, the companies that place them and the journals taking their money exhibit a complete disregard for global consensus on avoiding conflicts of interest in global health in the marketing of breast-milk substitutes and contribute significantly to undermining support for breastfeeding among health and scientific opinion leaders which, by extension, undermines breastfeeding in the general population.

Scientific publications that rely on advertising revenue should have advertising, paid supplements and sponsorship policies aligned with global and regional public health guidance, and sound conflict of interest safeguards. Leading professional associations have made changes to their sponsorship policies in recent years. In 2014, the International Society for Social Pediatrics \& Child Health published a position statement calling for the ending of all sponsorship from manufacturers of commercial formula products to paediatric associations. ${ }^{19}$ In 2019 , the Royal College of Paediatrics and Child Health stated that it would no longer accept funding from formula milk companies. ${ }^{20}$ In 2019, the British Medical Journal and its affiliated publications committed to no longer receive funding from breast-milk substitute manufacturers. ${ }^{21}$ Lake et al (2019) made a call to South African health and nutrition journals to follow suit. ${ }^{22}$

Although some journals may need to generate income through advertising, we urge editors to establish transparent policies stipulating what classes of adverts are allowed, guided by medical and public health consequences and national and international policies. Here we raise the example of infant formula, but the issue applies to other harmful commercial influences on health including tobacco, unhealthy foods, and alcohol. Similar issues regarding advertising of drugs by pharmaceutical 
companies in medical journals were raised in recent years. ${ }^{23}$

We urge all scientific journals and publishers to refrain from accepting funding from manufacturers and distributors of breast-milk substitutes or commercial formula products, in accordance with the Code. Journals and publishers must prioritise public health over profit; otherwise, they will amplify the estimated loss of 823000 children's lives each year due to sub-optimal breastfeeding. ${ }^{24}$

\section{Author affiliations}

${ }^{1}$ School of Public Health, University of the Western Cape Faculty of Community and Health Sciences, Cape Town, South Africa

${ }^{2}$ Centre for Health Science and Law, Ottawa, Ontario, Canada

${ }^{3} \mathrm{JB}$ Consultancy, Johannesburg, Gauteng, South Africa

${ }^{4}$ Dietetics \& Nutrition, University of the Western Cape Faculty of Community and Health Sciences, Cape Town, South Africa

${ }^{5}$ Division of Human Nutrition, Stellenbosch University-Tygerberg Campus, Cape Town, South Africa

${ }^{6}$ HIV Prevention Research Unit, Medical Research Council of South Africa,

Tygerberg, South Africa

${ }^{7}$ Department of Paediatrics, University of Pretoria Faculty of Health Sciences,

Pretoria, South Africa

${ }^{8}$ Children's Institute, Department of Paediatrics and Child Health, University of Cape Town, Cape Town, South Africa

${ }^{9}$ Neonatology, University of Cape Town Faculty of Health Sciences, Observatory, Western Cape, South Africa

${ }^{10}$ Paediatrics and Child Health, University of the Witwatersrand Faculty of Health Sciences, Johannesburg, Gauteng, South Africa

${ }^{11}$ Paediatrics and Child Health, University of Cape Town Faculty of Health Sciences, Observatory, Western Cape, South Africa

${ }^{12}$ Red Cross War Memorial Children's Hospital, Rondebosch, Western Cape, South Africa

${ }^{13}$ Program of Social Sciences and Health, FLACSO Argentina, Buenos Aires, Argentina

${ }^{14}$ International Society for Social Pediatrics and Child Health, Newcastle-upon-Tyne, UK

${ }^{15}$ International Society for Social Pediatrics and Child Health, Jacksonville, Florida, USA

${ }^{16}$ Department of Pediatrics, University of Florida College of Medicine-Jacksonville, Jacksonville, Florida, USA

${ }^{17}$ Giovine-Clark Consultancy, Coxsackie, New York, USA

${ }^{18}$ Institute for Physical Activity and Nutrition, Deakin University, Geelong, Melbourne, Australia

${ }^{19}$ Health Systems Research Unit, South African Medical Research Council,

Tygerberg, South Africa

Twitter Catherine Pereira-Kotze @KatiePNutrition, Bill Jeffery @BillFoodLaw, Jane Badham @jbadham, Ameena Goga @ameenagoga, Lori Lake @lorilakethetha, Jeffrey Goldhagen @JeffreyGoldhag1 and Phillip Baker @philbakernz

Contributors $\mathrm{CP}-\mathrm{K}$ coordinated the conceptualisation and writing of the original draft of the Comment, and this was reviewed by all 16 co-authors.

Funding $\mathrm{CP}-\mathrm{K}$ received support from the DSI/NRF Centre of Excellence in Food Security UID 91490.

Competing interests None declared.

Patient consent for publication Not applicable.

Ethics approval This study does not involve human participants.

Provenance and peer review Not commissioned; internally peer reviewed.

Data availability statement All data rekevant to the study are included in the article.

Open access This is an open access article distributed in accordance with the Creative Commons Attribution Non Commercial (CC BY-NC 4.0) license, which permits others to distribute, remix, adapt, build upon this work noncommercially, and license their derivative works on different terms, provided the original work is properly cited, appropriate credit is given, any changes made indicated, and the use is non-commercial. See: http://creativecommons.org/ licenses/by-nc/4.0/.

\section{ORCID iDs}

Catherine Pereira-Kotze http://orcid.org/0000-0003-3061-6511

Bill Jeffery http://orcid.org/0000-0003-2261-4700

Elizabeth C Swart http://orcid.org/0000-0002-7786-3117

Lisanne du Plessis http://orcid.org/0000-0003-0599-7500

Ameena Goga http://orcid.org/0000-0002-2394-6486

Lori Lake http://orcid.org/0000-0002-1039-3819

Haroon Saloojee http://orcid.org/0000-0002-8298-7210

Christiaan Scott http://orcid.org/0000-0003-3874-1704

Raul Mercer http://orcid.org/0000-0002-8616-0827

Tony Waterston http://orcid.org/0000-0001-7829-6831

Jeffrey Goldhagen http://orcid.org/0000-0001-7661-1551

Phillip Baker http://orcid.org/0000-0002-0802-2349

Tanya Doherty http://orcid.org/0000-0003-1592-0080

\section{REFERENCES}

1 Baker P, Russ K, Kang M, et al. Globalization, first-foods systems transformations and corporate power: a synthesis of literature and data on the market and political practices of the transnational baby food industry. Global Health 2021;17:58.

2 Boyle RJ, Shamji MH. Allergy societies and the formula industry. Clin Exp Allergy 2021;51:1260-1.

3 Munblit D, Crawley H, Hyde R, et al. Health and nutrition claims for infant formula are poorly substantiated and potentially harmful. $B M J$ 2020;369:m875.

4 Munblit D, Perkin MR, Palmer DJ, et al. Assessment of evidence about common infant symptoms and cow's milk allergy. JAMA Pediatr 2020;174:599-608.

5 Rollins NC, Bhandari N, Hajeebhoy N, et al. Why invest, and what it will take to improve breastfeeding practices? Lancet 2016;387:491-504.

6 Bailey R. Scrutinizing Industry-Funded science: the crusade against conflicts of interest. American Council on science and health. New York: ACSH, 2008. Available: https://www.acsh.org/sites/default/ files/111408281-Scrutinizing-Industry-Funded-Science-TheCrusade-Against-Conflicts-of-Interest.pdf [Accessed 23 Nov 2021.].

7 Grummer-Strawn LM, Zehner E, Stahlhofer M, et al. New World Health organization guidance helps protect breastfeeding as a human right. Matern Child Nutr 2017;13:e12491.

8 World Health Assembly (WHA). Maternal, infant, and young child nutrition: Safeguarding against possible conflicts of interest in nutrition programmes - draft approach for the prevention and management of conflicts of interest in the policy development and implementation of nutrition programmes at country level. Geneva: WHO, 2018. Available: https://apps.who.int/iris/handle/10665/ 274165[Accessed 23 Nov 2021].

9 World Health Organization (WHO). Addressing and managing conflicts of interest in the planning and delivery of nutrition programmes at country level. Report of a technical consultation convened in Geneva, 2015. Available: https://apps.who.int/ iris/bitstream/handle/10665/206554/9789241510530_eng.pdf; jsessionid=AA30BE84E1CF7789524E2209BC9A1271? sequence $=1$ [Accessed 27 Jan 2022].

10 World Health Organization (WHO). International Code of marketing of breast-milk substitutes. Geneva: WHO, 1981. Available: https://www. who.int/publications/i/item/9241541601 [Accessed 27 Jan 2022].

11 Morgan S, Waterston T, Kerac M. Infant formula advertising in medical journals: a cross-sectional study (and struggle to publish), 2018. Field exchange 58. p29.. Available: www.ennonline.net/fex/58/ infantformulaadvertising [Accessed: 25 Jan 2022].

12 Morgan SA, Waterston T, Kerac M. Formula adverts have no place in medical journals. BMJ 2019;364:I369.

13 European Commission. Regulation (EU) 2016/127 of 25 September 2015 supplementing regulation (EU) NO 609/2013 of the European Parliament and of the Council as regards the specific compositional and information requirements for infant formula and follow-on formula and as regards requirements on information relating to infant and young child feeding. Off $J$ Eur Union 2015.

14 World Health Organization (WHO), UNICEF \& the International Baby Food Action Network (IBFAN). Marketing of Breast-milk Substitutes: National Implementation of the International Code - Status Report 2020. New York: UNICEF, 2020. Available: https://www.who.int/ publications/i/item/9789240006010 [Accessed 23 Nov 2021]. 
15 Regulation (EU) 2013/609 of 12 June 2013 of the European Parliament and of the Council on food intended for infants and young children, food for special medical purposes, and total diet replacement for weight control. L181/35 29.6.2013, 2013. Official Journal of the European UnionEuropean Commission. Available: https://eur-lex.europa.eu/legal-content/EN/TXT/?uri=OJ:L:2013:181: TOC [Accessed 2 Feb 2022].

16 The Infant Formula and Follow-on Formula (England) Regulations 2007 No. 3521, 20, 2007. Available: https://www.legislation.gov.uk/ uksi/2007/3521/made [Accessed : 27 Jan 2022]

17 Cacho NT, Lawrence RM. Innate immunity and breast milk. Front Immunol 2017;8:584.

18 NEOVITA Study Group. Timing of initiation, patterns of breastfeeding, and infant survival: prospective analysis of pooled data from three randomised trials. Lancet Glob Health 2016;4:3266-75

19 Waterston T. Sponsorship of paediatricians/paediatric societies by the baby feeding industry (ISSOP position statement 4) (PP.
1-16), 2014. Available: https://www.issop.org/cmdownloads/ issop-position-statement-4-sponsoring-baby-feeding-industry/\# [Accessed 31 Oct 2021].

20 Royal College of Paediatrics and Child Health (RCPCH). RCPCH statement on relationship with formula milk companies, 2019. Available: https://www.rcpch.ac.uk/news-events/news/rcpchstatement-relationship-formula-milk-companies [Accessed 31 Oct 2021]

21 Godlee F, Cook S, Coombes R, et al. Calling time on formula milk adverts. BMJ 2019;364:11200.

22 Lake L, Kroon M, Sanders D, et al. Child health, infant formula funding and South African health professionals: eliminating conflict of interest. S Afr Med J 2019;109:902-6.

23 Fugh-Berman A, Alladin K, Chow J. Advertising in medical journals: should current practices change? PLoS Med 2006;3:e130.

24 Victora CG, Bahl R, Barros AJD, et al. Breastfeeding in the 21st century: epidemiology, mechanisms, and lifelong effect. Lancet 2016;387:475-90. 